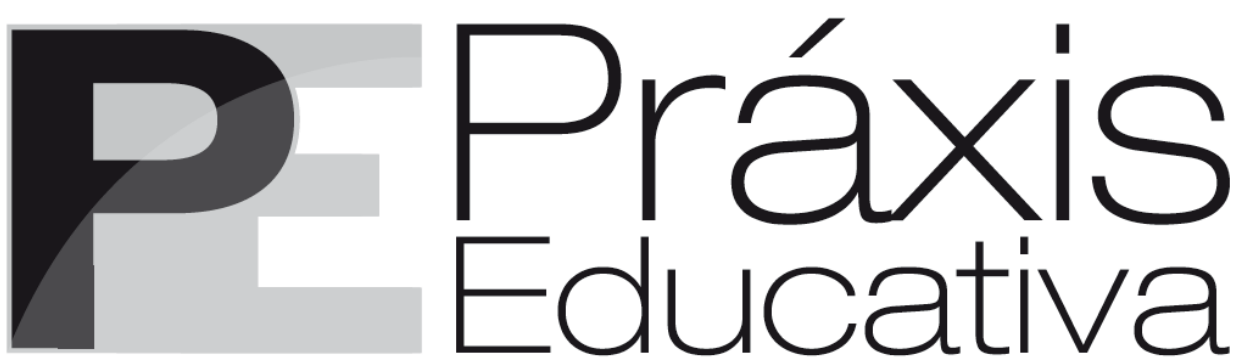

ISSN 1809-4309 (Versão online)

DOI: 10.5212/PraxEduc.v.11i3.0003

\title{
Sobre Foucault e a verdade: as relações entre currículo e avaliações em larga escala $^{*}$
}

\section{About Foucault and the truth: the relations between curriculum and large- scale assessment}

\section{Sobre Foucault y la verdad: las relaciones entre el curriculum y evaluaciones a gran escala}

\author{
Rosimar Serena Siqueira Esquinsani* \\ Jarbas Dametto ${ }^{* * *}$
}

Resumo: Este texto apresenta resultados de uma pesquisa de base documental e bibliográfica, pautada por uma metodologia analítico-reconstrutiva, cujo escopo incide sobre a noção de "verdade" em Michel Foucault (1926-1984). Explora-se seu potencial como aparato crítico para a abordagem de políticas educacionais, mormente em relação ao currículo e a sua interface com as avaliações em larga escala. Frente a esse intento, recorre-se à obra foucaultiana e ao debate acerca da verdade como fenômeno situado no âmbito das práticas e da construção política da realidade. A partir dessa lógica, aproxima-se esse aparato crítico à interpretação das políticas educacionais, em especial daquelas que se utilizam de indicadores de qualidade como modo de legitimação, bem como de ações advindas dessa legitimação, entre elas os currículos escolares. Como resultado, salienta-se que as avaliações em larga escala são capazes de moldar o currículo escolar, impondo-se como porta-voz da verdade em relação ao projeto de sociedade em pauta. Palavras-chave: Currículo. Avaliações em larga escala. Michel Foucault.

\begin{abstract}
This paper presents results of documental and bibliographical based research, drawn from an analytical-reconstructive methodology whose scope lies in the notion of "truth" in Michel Foucault (19261984). We explore its potential as a critical apparatus for the approach of education policies, mainly regarding curriculum and its interface with large-scale assessments. Given this intent, we resort to Foucault's work and to the debate about truth as a phenomenon situated within the practices and political construction of reality. From this logic, we approach this critical apparatus to the interpretation of education policies, especially those that use qualitative indicators as a mode of legitimation, as well as actions resulting from this legitimation, including school curricula. As a result, we highlight that these large-scale assessments are able to shape the school curriculum, establishing itself as the spokesperson of truth in relation to the societal project in question.
\end{abstract}

Keywords: Curriculum. Large-scale assessments. Michel Foucault.

\footnotetext{
* Pesquisa financiada pelas seguintes agências de fomento: Conselho Nacional de Desenvolvimento Científico e Tecnológico (CNPq) e Fundação de Amparo à Pesquisa do Estado do Rio Grande do Sul (FAPERGS).

** Professora da Universidade de Passo Fundo (UPF). E-mail: <rosimaresquinsani@upf.br>.

*** Professor da Universidade de Passo Fundo (UPF). E-mail: <jarbas@upf.br>.
} 
Resumen: El texto presenta los resultados de una investigación de base documental y bibliográfica, guiada por una metodología analítica reconstructiva cuyo ámbito incide sobre la noción de "verdad" en Michel Foucault (1926-1984). Se explota su potencial como un aparato crítico para abordar políticas educativas, especialmente en relación con el currículum y con su interrelación con las evaluaciones a gran escala. Teniendo en cuenta esta intención, se recurre a la obra de Foucault y al debate acerca de la verdad como un fenómeno situado en el ámbito de las prácticas y de la construcción política de la realidad. Desde esta lógica, se acerca este aparato crítico a la interpretación de las políticas educativas, en especial a aquellas que hacen uso de indicadores de calidad como modo de legitimidad, así como las acciones resultantes de esta legitimidad, entre ellas los programas escolares. Como resultado, se observa que las evaluaciones a gran escala son capaces de dar forma al currículum, estableciéndose como el portavoz de la verdad en relación con el proyecto social en pauta.

Palabras clave: Currículum. Evaluación a gran escala. Michel Foucault.

\section{Introdução}

[...] lá onde existe poder, lá onde é preciso que exista poder, lá onde se quer mostrar que é efetivamente ali que reside o poder, e bem, é preciso que exista o verdadeiro; e lá onde não existe o verdadeiro, lá onde não existe manifestação do verdadeiro, então é porque ali o poder não está, ou é muito fraco ou é incapaz de ser poder. (FOUCAULT, 2009, p. 16).

Embora algumas periodizações e sistematizações da obra foucaultina situem a questão da "verdade" e o interesse prioritariamente epistemológico do filósofo francês nas suas primeiras publicações, é inegável que sua obra, como um todo, foi atravessada pela problematização do saber e de seus efeitos práticos: o modo como verdades foram arquitetadas em diferentes contextos históricos, e a forma como elas incidiram sobre a vida dos sujeitos a elas atrelados. Foucault não tentou ser, em sentido pleno, um epistemólogo ou um historiador do conhecimento, assim como não buscou constituir uma análise do Poder do Estado: ele ativamente escapa dos trilhos de uma epistemologia ao debruçar-se sobre o saber e não sobre a ciência, diferenciação a ser esclarecida com mais detalhes à frente; bem como evita teorias sobre o Estado ao problematizar as minúcias dos pequenos poderes e saberes cotidianos, que, com sua tênue presença, saturam a experiência de vida compondo o que ele denomina como modos de subjetivação. Em um de seus cursos finais, em poucas palavras, o autor descreve algumas das rupturas que tentou realizar, que garantiram à sua obra pertinência e originalidade:

\footnotetext{
Substituir a história dos conhecimentos pela análise histórica das formas de veridicção, substituir a história das dominações pela análise histórica dos procedimentos de governamentalidade, substituir a teoria do sujeito ou a história da subjetividade pela análise histórica da pragmática de si e das formas que ela adquiriu, eis as diferentes vias de acesso pelas quais procurei precisar um pouco a possibilidade de uma história do que se poderia chamar de 'experiências'. (FOUCAULT, 2011, p. 7, grifo do autor).
}

Enfatizando a dimensão da experiência, Foucault põe em suspenso qualquer sentido transcendental ao saber, ao poder, bem como ao sujeito. Dentro dos campos e das temáticas abordadas pelo autor, em sua concepção, não há uma verdade efetiva oculta nos fatos, nem múltiplas tentativas históricas de reconhecê-la e trazê-la ao discurso. Antes se fabricam verdades, dado que o verdadeiro não tem por função descrever realidades tal quais são, mas cumprir frente à vida real um papel constitutivo. A realidade só existe ao homem por sua tradução discursiva, que é, por sua vez, arbitrária e politicamente construída.

Práxis Educativa, Ponta Grossa, p. 577-589, v. 11, n. 3, set./dez. 2016 Disponível em: <http://www.revistas2.uepg.br/index.php/praxiseducativa $>$ 
Foucault lançou esse olhar sobre diversas temáticas, saberes e práticas, indo da psiquiatria à medicina empírica, do pensamento antigo ao neoliberalismo, das prisões à sexualidade. Entretanto, poucos comentários efetivamente direcionaram-se à educação e, talvez nada, às políticas educacionais. Assim sendo, assume-se aqui o risco desta transposição ou desta "aplicação" de noções foucaultianas a campos distintos daqueles por ele indicados, risco este já assumido por diversos outros pesquisadores, partindo da premissa de que políticas educacionais, assim como todo ato político, mas não somente este, instauram-se em meio a complexas redes discursivas, que apoiam e são apoiadas por práticas sociais e institucionais, que, em conjunto, fazem emergir uma realidade e sua verdade.

Desta feita, este texto apresenta resultados de uma pesquisa de base documental e bibliográfica, pautada por uma metodologia analítico-reconstrutiva, cujo escopo incide sobre a noção de "verdade" em Michel Foucault (1926-1984), explorando seu potencial como aparato crítico para a abordagem de políticas educacionais, mormente em relação ao currículo e sua interface com as avaliações em larga escala, a partir dos recursos advindos da pesquisa científica. Os textos foram examinados a partir da metodologia da análise de conteúdo, utilizando-se a técnica da análise temática, cujo "[...] tema é a unidade de significação que se liberta naturalmente de um texto analisado, segundo critérios relativos à teoria que serve de guia à leitura" (BARDIN, 2007, p. 105).

Associada a essa perspectiva metodológica, o texto ensaia aproximações com o enfoque das epistemologias da política educacional (EEPE) (TELLO; MAINARDES, 2015), por entender que este "[...] é um dos modos possíveis de abordar a análise do campo da pesquisa em política educacional" (TELLO; MAINARDES, 2015, p. 155), em que "[...] os fundamentos teóricos e epistemológicos de uma pesquisa em política educacional devem permitir a compreensão de um objeto de estudo e não meramente a descrição" (TELLO; MAINARDES, 2015, p. 155).

Assume-se, ainda, que

[...] a concepção que temos da política educacional gera uma pressuposição sobre a pesquisa em política educacional e, neste sentido, o EEPE propõe a não neutralidade da produção de conhecimentos em política educacional e das diversas construções subjetivas que realiza o pesquisador sobre seu objeto de estudo. (TELLO; MAINARDES, 2015, p. 158).

Por fim, cumpre-se informar que o texto apresentado faz parte dos resultados parciais de uma pesquisa que objetiva estabelecer discussões sobre os conceitos e os procedimentos inerentes à prática da gestão da educação em redes e sistemas públicos de ensino, na qualidade de tema emergente na composição da atual agenda educacional.

\section{Situando a proposta de Foucault: a verdade e suas fabricações}

A proposta de análise foucaultiana toma a verdade como objeto, e, embora estejam relativamente habituados a localizá-la nas ciências, não é exatamente essa concepção do autor. Michel Foucault conceitua verdade como sendo um "[...] conjunto das regras segundo as quais se distingue o verdadeiro do falso e se atribui ao verdadeiro efeitos específicos de poder [...] conjunto de procedimentos regulados para a produção, a lei, a repartição, a circulação e o funcionamento dos enunciados" (FOUCAULT, 2002a, p. 13-14). Para ele, "[...] a ciência, o conhecimento objetivo, é somente um momento possível de todas essas formas pelas quais podese manifestar o verdadeiro" (FOUCAULT, 2009, p. 13). Tem-se, por esse prisma, no pensamento foucaultiano, uma ruptura tanto em relação ao método científico como mecanismo exclusivo de

Práxis Educativa, Ponta Grossa, p. 577-589, v. 11, n. 3, set./dez. 2016 Disponível em: <http://www.revistas2.uepg.br/index.php/praxiseducativa > 
veridicção - compreendida como discurso que toma o lugar da verdade, com valor ontológico ou referencial (BERTRAND, 2003) -, quanto às concepções tradicionais acerca da representação.

Foucault nega a afirmação tradicional da verdade como adequação - isto é, como correspondência entre uma coisa e a ideia que fazemos a seu respeito -, é porque, segundo ele, a coisa conhecida não pode separar-se dos quadros (dos "discursos") por meio dos quais os homens historicamente se representam as coisas; e o conhecimento, por seu turno, informando "dados objetivos", antes constitui seus objetos do que os reflete. (YAZBEK, 2012, p. 123).

Como pontua Veyne (2009, p. 99): "La inmensa mayoría de verdades en las diferentes épocas no son absolutamente verdaderas, aunque eso no las hace existir menos". Logo, o verdadeiro do qual fala Foucault não é aquilo que se distancia ao extremo do "falso" pelas vias de algum método ou pela adequação da linguagem, mas sim um recurso sobre o qual se alicerça o poder ou se justifica o ato de governar. Afirma o filósofo que "[...] seria muito difícil encontrar um exemplo de poder que não se exerça sem se acompanhar, de um modo ou de outro, de uma manifestação de verdade" (FOUCAULT, 2009, p.8-9). Além disso, a ruptura com a concepção do saber como fenômeno exclusivamente científico visou outros desdobramentos.

A noção de saber tinha por função colocar fora de terreno a oposição do científico e do não científico, a questão da ilusão e da realidade, a questão do verdadeiro e do falso, não para dizer que essas oposições não tinham um estado de causa, de sentido, de valor; eu quis dizer, simplesmente, que se tratava, com o saber, de colocar o problema em termos de práticas constitutivas de domínios de objetos e de conceitos no interior das quais as oposições do científico e do não científico, da ilusão e da realidade, do verdadeiro e do falso, poderiam assumir seus efeitos. Já a noção de poder tinha, essencialmente, por função substituir a noção de sistemas de representação: aqui a questão, o campo de análise, são os procedimentos, os instrumentos e as técnicas pelas quais se realizam efetivamente as relações de poder. (FOUCAULT, 2009, p. 20).

Tal coabitação do saber, ou do verdadeiro, junto às práticas de poder, não se dá de modo instrumental. Essa verdade não é, tão somente ou necessariamente, o aparato teórico do poder ou o seu manual de ação. "[...] esse verdadeiro, do qual a manifestação acompanha o exercício do poder, ultrapassa largamente os conhecimentos que são úteis para o governo" pontua Foucault (2009, p. 9). Tais formas de manifestação da verdade acompanhariam o exercício do poder desde a Antiguidade, condição na qual:

Não se tratava, igualmente, de organizar um conhecimento; não se tratava da organização de um sistema utilitário de conhecimento necessário ou suficiente para exercer o governo, mas tratava-se de um ritual de manifestação da verdade sustentada por um exercício de poder; de um certo número de relações que certamente não podem ser reduzidas ao nível da utilidade pura e simples. (FOUCAULT, 2009, p. 10-11).

Ao problematizar a relação entre saber e poder, e depois entre o poder e a verdade, Foucault realiza em sua obra, a princípio, uma ruptura com a noção, em voga em sua época, de "ideologia dominante", contrapondo a ela a sua concepção de discurso. Ele demarca a distinção de sua abordagem frente a tal noção sob os seguintes argumentos:

Se à noção de ideologia dominante eu tentei opor a noção de saber-poder, foi porque a essa noção de ideologia dominante, eu creio, pode-se fazer três objeções. Primeiramente, ela postula uma teoria incompleta ou uma teoria imperfeita da representação. Segundo, essa noção de ideologia dominante está indexada, pelo menos implicitamente e sem poder desembaraçar-se de modo claro, à oposição do verdadeiro e do falso, da realidade e da ilusão, do científico e do não científico, do racional e do irracional. Terceiro, enfim, sob a palavra dominante, depois de tudo, a noção de ideologia fica num impasse em relação a todos os mecanismos reais de assujeitamento, distanciando-se, de qualquer modo, do empreendimento e repassando-o a um terceiro,

Práxis Educativa, Ponta Grossa, p. 577-589, v. 11, n. 3, set./dez. 2016 Disponível em: <http://www.revistas2.uepg.br/index.php/praxiseducativa> 
recorrendo aos historiadores do saber para perceber como e porque em uma certa sociedade alguns dominam os outros. (FOUCAULT, 2009, p. 20).

Ainda sobre essa pertinente diferenciação entre a concepção de discurso foucaultiana e a noção de ideologia dominante, tem-se a seguinte demarcação, proposta por Veyne:

Los discursos son las gafas a través de las cuales, en cada época, los hombres han percebido las cosas, han pensado e han actuado; los discursos se imponen a los dominantes tanto como a los dominados; no son mentiras inventadas por aquéllos para engañar a éstos y justificar su dominación. (VEYNE, 2009, p. 37).

De tal modo, não haveria um endereçamento das ações do poder e do saber "de cima para baixo", nem um desconhecimento das verdades que envolvem o ato do poder. Em sua concepção, no poder há "envolvidos", sujeitos e instituições atrelados a discursos que incidem sobre todos, e não uma relação entre detentores e subjugados, tal qual se apresenta na noção de ideologia dominante.

Mais tardiamente em seu percurso investigativo, o autor propõe outra ruptura, talvez parcial, com sua própria noção de saber-poder, na tentativa de desvencilhar-se dos limites que ela apresenta, não a abandonando de todo, mas indo além dela, adentrando a problematização da verdade no ato de governar. "Grosso modo, se vocês quiserem, dois deslocamentos sucessivos: um da noção de ideologia dominante para essa noção de poder-saber e agora um segundo deslocamento da noção saber-poder para a noção do governo pela verdade" (FOUCAULT, 2009, p. 19). Uma transição na qual ele buscou "[...] dar um conteúdo positivo e diferenciado a esses dois termos saber e poder" (FOUCAULT, 2009, p. 21).

Sua concepção de governo não se resume aos atos do Estado, quando menciona tal termo, ele abarca os diversos "[...] mecanismos e procedimentos destinados a conduzir os homens, a dirigir a conduta dos homens, a conduzir a conduta dos homens" (FOUCAULT, 2009, p. 21). Tais atos de governamentalidade, afirma o autor, não são possíveis por uma condição de ignorância dos governados, mas pela ostentação de uma verdade:

[...] não é porque os governados ignoram aquilo que se passa ou que alguns entre eles sabem enquanto outros não sabem, mas é o contrário: é porque eles sabem e na medida em que sabem, na medida que a evidência disso que se passa é efetivamente consciente a todo mundo, é nessa medida que as coisas não se modificam. É precisamente esse o princípio do terror: o terror não é uma arte de governar que se oculta nos seus fins, nos seus motivos e nos seus mecanismos, o terror é precisamente a governamentalidade no seu estado nu, em estado cínico, em estado obsceno. No terror é a verdade e não a mentira que imobiliza: é a verdade que ele deixa, é a verdade que se rende ela mesma, pela sua evidência manifesta por toda parte, que se rende intangível e inevitável. (FOUCAULT, 2009, p. 26).

$\mathrm{Na}$ concepção do autor, a verdade que perpassa o ato de governar não teria pelas vias da ocultação ou da posse restrita à classe dominante os seus efeitos de poder (por um estado de não conscientização, como se propunha na noção de ideologia dominante), antes, o teria pela ampla veiculação, pela demonstração icônica e monumental. Atos políticos, então, necessitariam de uma demonstração do verdadeiro a eles correlata, discursos que atestem a sua pertinência e legitimidade, emitidos por quem e de um lugar que possua este direito de enunciação histórica e tradicionalmente construído, direito outrora possuído pelos oráculos, pelos adivinhos, pelos astros, pelo clero e suas escrituras, e, hoje, pela universidade, pelo cientista, pela mídia ou pelos institutos de pesquisa.

Foucault trabalha com jogos de verdade e não de linguagem. Desse modo, tem-se no autor um olhar privilegiado, também sobre o âmbito não discursivo que se relaciona à construção

Práxis Educativa, Ponta Grossa, p. 577-589, v. 11, n. 3, set./dez. 2016 Disponível em: <http://www.revistas2.uepg.br/index.php/praxiseducativa > 
do saber. As análises foucaultianas sobre a loucura e sobre as penalidades expressam enfaticamente tal imbricação entre a construção do saber e aquilo que se faz nas instituições e na atuação dos sujeitos que operam determinadas funções na sociedade (VEYNE, 2009; MACHADO, 2007). Analisar discursos com os quais se "enuncia o verdadeiro", nesses termos, não seria debruçar-se somente sobre o que é dito ou escrito, muito menos vasculhar o implícito nesses atos linguageiros. Antes, caberia abarcar aquilo que é feito, a materialidade do saber como prática: os discursos cartografam o que as pessoas fazem e pensam realmente, por vezes sem saber que o fazem e que assim pensam. Não há causa e efeito entre o discurso e a realidade, elas se tramam (VEYNE, 2009).

Com referência a Nietzsche, Foucault (2002b) propõe que não há uma origem no conhecimento, nem uma existência natural dele, mas sim "fabricações", ou seja, atos originários construídos no bojo de relações de poder, que atendem a arranjos políticos, epistêmicos e/ou técnicos específicos:

Temos que admitir que o poder produz saber (e não simplesmente favorecendo-o porque o serve ou aplicando-o porque é útil); que poder e saber estão diretamente implicados; que não há relação de poder sem constituição correlata de um campo de saber, nem saber que não suponha e não constitua ao mesmo tempo relações de poder. (FOUCAULT, 1984, p. 30).

O vínculo entre as coisas a conhecer e o saber sobre elas é um procedimento arbitrário eminentemente político; uma relação, por vezes, violenta entre a concretude dos fenômenos e a sua apreensão discursiva, que os torna objetos de um campo do saber. Pontua o filósofo que "[...] à solenidade de origem, é necessário opor, em bom método histórico, a pequenez meticulosa e inconfessável dessas fabricações, dessas invenções" (FOUCAULT, 2002b, p. 16). O autor acrescenta:

Se quisermos realmente conhecer o conhecimento, saber o que ele é, apreendê-lo em sua raiz, em sua fabricação, devemos nos aproximar, não dos filósofos, mas dos políticos, devemos compreender quais são as relações de luta e de poder. E é somente nessas relações de luta e de poder - na maneira como as coisas entre si, os homens entre si se odeiam, lutam, procuram dominar uns aos outros, querem exercer, uns sobre os outros, relações de poder - que compreendemos em que consiste o conhecimento. (FOUCAULT, 2002b, p. 23).

"A verdade é deste mundo", afirma Foucault (2002c, p. 12), é nas relações de força em uma sociedade que ela emerge, elegendo formas específicas de enunciar o verdadeiro e apontando os objetos a conhecer. O autor debruçou-se sobre alguns dos modos de veridicção que pressupõem fidúcia, confiança no que está sendo dito - historicamente presentes do ocidente e traçou algumas observações sobre os modos contemporâneos, como aponta Castro (2009):

Foucault distingue cinco características historicamente importantes da "economia política" da verdade em nossas sociedades: ela está centrada no discurso científico e nas instituições que o produzem; está submetida a uma constante incitação política e econômica; é objeto de difusão e consumo; é produzida e distribuída sob o controle dominante de grandes aparatos políticos e econômicos; é a colocação em jogo do debate político e das lutas sociais. (CASTRO, 2009, p. 423, grifo do autor).

Nessa descrição, têm-se alguns locais por excelência da enunciação do verdadeiro - a ciência, o âmbito político instituído, o cenário econômico e seus operadores, bem como alguns de seus efeitos: a construção de agendas políticas, o evidenciar de determinados fatos, situações ou conflitos; enfim, a construção de determinados objetos e os posicionamentos frente a essa realidade. Um rápido olhar sobre a política em geral, e sobre as políticas educacionais em específico, evidencia a fabricação e a apropriação de verdades que justificam, amparam, 
potencializam atos políticos: agências de pesquisa, públicas e privadas, que constroem dados estatísticos, pesquisas encomendadas, comparações entre dados internacionais, indicadores socioeconômicos, indicadores de qualidade, dentre tantos outros dados que "amparam medidas técnicas", que, em última instância, incidem sobre as escolhas, as ações e os destinos dos sujeitos envolvidos nos mais diversos setores da vida em sociedade.

\section{Políticas educacionais e suas verdades: o currículo e as avaliações em larga escala}

Os atos políticos referentes à gestão de sistemas e redes de ensino, dentro do proposto anteriormente, assumem o caráter de políticas educacionais, referidas "[...] como a ação política, como fenômeno educativo possível de ser investigado" (TELLO, 2012, p. 57). Tais atos, por sua condição de construto social e político, não prescindem de esforços para a edificação de verdades que os justifiquem, dando legitimidade a opções e a caminhos apontados pelas instâncias governamentais ou por outros agentes da sociedade, com demandas e projetos específicos de desenvolvimento econômico-social.

Se, para Michel Foucault a verdade é deste mundo, como já referido, a verdade também “[...] não existe fora do poder ou sem poder" (FOUCAULT, 2002a, p. 12). Dirá o autor que "a própria verdade é poder" (FOUCAULT, 2002a, p. 14). Diante de uma relação tão orgânica entre verdade e poder, é lícito supor que a verdade também corresponde ao - ou responde pelo poder.

Assim, as políticas educacionais não fugiriam dessa articulação entre verdade pronunciada, relatada, legitimada - e poder: poder-saber; poder-fazer; poder-legitimar; poderpermitir... Os movimentos e as ações de políticas educacionais também considerariam essa relação. Assim, avaliações em larga escala e suas interfaces e alcances (entre estas, o currículo) igualmente representariam a relação verdade-poder, disposta à pesquisa acadêmica, à ação social, à reação de educadores, entre outros movimentos.

Acreditamos de tal modo que não é possível a existência de políticas educacionais desprovidas de um sentido de construção social e histórica, ou uma ação de política educacional neutra e acima dos debates conjunturais de sua época. Essa é a nossa "[...] perspectiva epistemológica, para o caso das pesquisas em política educacional, a cosmovisão que [assumimos] para guiar a [...] pesquisa" (TELLO; MAINARDES, 2015, p. 156), uma vez compreendido que:

\footnotetext{
As políticas educativas expressam as ideologias que se configuram a partir da materialidade social. Assim, compreender o verdadeiro significado de uma política educativa só é possível com a apreensão da lógica global de um determinado sistema de produção, a qual gera uma forma específica de consciência social, trazendo implicações práticas em diferentes esferas da sociedade. (MASSON, 2013, p. 69).
}

No contexto contemporâneo da educação, nacional e internacional, vê-se uma ênfase persistente sobre os indicadores de qualidade educacional, desenvolvidos por meio de pesquisas por amostragem junto a alunos e instituições, pela abordagem da opinião de experts ou do mercado de trabalho, e, principalmente, por meio de avaliações externas aplicadas a amplos recortes da população escolar, gerando resultados que, via de regra, são organizados em rankings que demonstram "a verdade" (ou constroem um discurso de veridicção) sobre os diversos sistemas educacionais e as instituições que os compõem, principalmente no que tange ao conceito de qualidade.

É justamente nesse contexto que figuram as avaliações em larga escala, em geral caracterizadas por serem externas à rede de ensino, ao sistema educacional ou à instituição a qual 
se destinam, pautando-se em testes padronizados aplicados a uma população de grande porte (séries ou anos escolares, faixas etárias ou terminalidades, etc.) e baseadas na teoria de resposta ao item. Tais avaliações comumente centram seu foco no rendimento do aluno e no desempenho e na competitividade dos sistemas de ensino, nutrindo a agenda de debates com informações que podem ser analisadas e compreendidas por toda sorte de teorias e estatísticas.

São exemplos de avaliações em larga escala: a) o Sistema de Avaliação da Educação Básica - Saeb, composto pela Avaliação Nacional da Educação Básica - Aneb, pela Avaliação Nacional do Rendimento Escolar - Anresc, também conhecida como Prova Brasil, e pela recente Avaliação Nacional da Alfabetização - ANA; b) o Exame Nacional do Ensino Médio - ENEM; c) o Exame Nacional de Desempenho dos Estudantes - ENADE; d) o Programme for International Student Assessment - PISA, além de uma série de avaliações em larga escala que podem ser desenvolvidas em nível local e regional, à critério dos sistemas de ensino.

No que concerne a essa avaliação educacional, é necessário sopesar que

[...] a construção de indicadores de qualidade assume grande complexidade, por se tratar de um campo aplicado das ciências sociais que lida com a construção de modelos para valorar políticas, programas, projetos e ações educativas que além de expressarem concepções teóricas e abordagens determinadas, envolvem também aspectos vinculados aos interesses sócio-políticos de determinados grupos em confronto e suas representações sobre qualidade em educação. Nesse sentido, o cuidado epistemológico e metodológico, bem como o enfoque sociológico sobre as representações sociais acerca do que se está avaliando são aspectos fundamentais para a definição de indicadores e para o conhecimento sobre o fenômeno que está sendo avaliado, no caso a qualidade da educação. (FERREIRA; TENÓRIO, 2010, p. 72).

A partir das avaliações em larga escala, são produzidos uma sorte de documentos e textos, entre os quais relatórios técnicos, tabelas, gráficos, bem como colunas de opinião e demais comentários midiáticos, que replicam as verdades pronunciadas (e provadas) pelos resultados das avaliações em larga escala, dando a elas uma marcante presença, que toca os sujeitos que foram alvos dessas pesquisas: professores, gestores, alunos, propondo novas condutas, novos objetivos, elencando prioridades, reforçando algumas práticas e conteúdos e boicotando outros.

Diversas críticas são feitas a tais métodos de avaliação, seja em seu caráter evidentemente performático, que gera intencionalmente competição e uma forma de marketing pernicioso por meio da publicação de resultados (BALL, 2004, 2010); seja pela série de fatores externos à ação escolar envolvidos nos resultados obtidos em avaliações externas e pela parcialidade, senão pela precariedade de seus métodos; bem como pela perspectiva produtivista e competitiva que fomentam no ambiente escolar (ANDRADE, 2011).

A despeito de algumas resistências, tais dispositivos persistem e progridem revelando a "verdade" sobre a ação educacional, ou seja, enunciando discursos subjetivantes sobre ela, supostamente natural, a-histórica e não arbitrária noção de "qualidade", atributo constatável que, supostamente, residiria em todo processo empreendido pela educação, a espera de um método fidedigno que o revele e o mensure (no caso, as notas e os rankings). Entretanto, se sustentarmos a premissa que "[...] não há neutralidade na produção do conhecimento, pois todo processo que envolve o conhecimento está atrelado ao intercâmbio material dos homens" (MASSON, 2013, p. 61), as ações de políticas educacionais - entre elas as avaliações em larga escala e suas relações materiais mais ou menos tangíveis, incluindo o(s) currículo(s) -, também não podem assumir ares de neutralidade. 
Igualmente não é neutro o discurso oficial sobre o assunto, quando assinala e legitima a relação entre o que é ensinado na escola (currículo) e o que é "cobrado" nas avaliações em larga escala.

\begin{abstract}
A qualidade do conteúdo aprendido nas escolas é verificada por meio de avaliações para medir as competências e as habilidades desenvolvidas pelos alunos. O processo guarda semelhanças ao que os professores fazem para avaliar se seus alunos aprenderam ou não uma determinada matéria. O Sistema Nacional de Avaliação da Educação Básica (Saeb) apresenta testes de habilidades e competências, construídos por especialistas de cada área, e utiliza as mais avançadas técnicas estatísticas para diagnosticar o nível educacional de determinadas séries. (BRASIL, 2004, p. 11).
\end{abstract}

Se as avaliações em larga escala são capazes de produzir veridicções sobre o conhecimento e o resultado "materializável" desse conhecimento, por que não o fariam com o currículo disciplinar, "[...] entendido como consequência de princípios de organização curricular baseados na lógica das ciências ou na natureza do conhecimento" (LOPES, 2008, p. 43)? Consideramos que

[...] toda política curricular é uma política cultural, pois o currículo é fruto de uma seleção e produção de saberes: campo conflituoso de produção de cultura, de embate entre pessoas concretas, concepções de conhecimento e aprendizagem, formas de imaginar e perceber o mundo. Assim, as políticas curriculares não se resumem apenas a propostas e práticas enquanto documentos escritos, mas incluem os processos de planejamento, vivenciados e reconstruídos em múltiplos espaços e por múltiplas singularidades no corpo social da educação. (BRASIL, 2010, p. 19).

Desse modo, a simples existência - legitimada pelos órgãos governamentais que as concebem, produzem e sustentam - de avaliações em larga escala, seus resultados e o caráter de verdade expresso por eles implicaria sim, entre outras ações, na

[...] definição de novas políticas públicas, de projetos de implantação e modificação de currículos, de programas de formação continuada dos docentes e, de maneira decisiva, na definição de elementos para a tomada de decisões que visem a provocar um impacto, ou seja, mudanças no pensar e no agir dos integrantes do sistema. (VIANNA, 2005, p. 17, grifos nossos).

Assim, o currículo em vigor não seria apenas um arrolamento de conteúdos objetivados, mas uma construção histórica que legitima verdades e grupos sociais, indicando quais são os conteúdos e os conceitos válidos e relevantes em um projeto social.

[...] as funções que o currículo cumpre como expressão do projeto de cultura e socialização são realizadas através de seus conteúdos, de seu formato e das práticas que cria em torno de si. Tudo isso se produz ao mesmo tempo: conteúdos (culturais ou intelectuais e formativos), códigos pedagógicos e ações práticas através dos quais se expressam e modelam, conteúdos e formas. (SACRISTÁN, 2000, p. 16).

A questão articuladora de toda concepção e política curricular está intrinsecamente relacionada ao projeto de sociedade que se deseja formar. Contudo, para escolha de um projeto de sociedade, é preciso a compreensão de que aquele projeto representa a "verdade" histórica, construída e consolidada a partir de instrumentos de veridicção - e discurso - que garantem tal legitimidade, uma vez que

[...] em todas as sociedades a produção do discurso é ao mesmo tempo controlada, selecionada, organizada e redistribuída por certo número de procedimentos que têm por função conjurar seus poderes e perigos, dominar seu acontecimento aleatório, esquivar sua pesada e terrível materialidade. (FOUCAULT, 2002c, p. 9).

Assim, o currículo representa não apenas uma discussão do que merece ser ensinado, mas

Práxis Educativa, Ponta Grossa, p. 577-589, v. 11, n. 3, set./dez. 2016 Disponível em: <http://www.revistas2.uepg.br/index.php/praxiseducativa> 
a razão pela qual aquele conteúdo deve ser ensinado em uma condição de verdade. A gênese do currículo estaria imbricada na lógica foucaultiana de controle, de seleção, de organização e de redistribuição do que será não apenas discurso, mas conhecimento válido para novas gerações. Nessa perspectiva, as questões de fundo são:

Qual é o tipo de ser humano desejável para um determinado tipo de sociedade? Será a pessoa racional e ilustrada do ideal humanista de educação? Será a pessoa otimizadora e competitiva dos atuais modelos neoliberais de educação? Será a pessoa ajustada aos ideais de cidadania do moderno estado-nação? Será a pessoa desconfiada e crítica dos arranjos sociais existentes preconizada nas teorias educacionais críticas? [...] No fundo das teorias do currículo está, pois, uma questão de "identidade" ou de "subjetividade". (SILVA, 2007, p. 14-15, grifos do autor).

A condição de status de verdade, a qual ascende contemporaneamente a avaliação em larga escala, sublinha tacitamente uma padronização mínima em termos de conteúdos, de procedimentos e/ou de saberes a serem ensinados (e aprendidos?) em escolas de Educação Básica de todo o país, fornecendo um estofo discursivo que atribui verdade àquele conhecimento em pauta. A perspectiva de heterogeneidade curricular não vinga em um modelo onde, subliminarmente, é válido e verdadeiro o conteúdo "retomado" nas avaliações padronizadas.

Tal relação fica ainda mais palpável nos documentos que representam posições oficiais, em que as avaliações em larga escala ascendem como uma condição de verdade na medida em que é tomada governamentalmente como uma prestação de contas.

O Ideb é um dos eixos do PDE [Plano de Desenvolvimento da Educação] que permite realizar uma transparente prestação de contas para a sociedade de como está a educação em nossas escolas. Assim, a avaliação passa a ser a primeira ação concreta para se aderir às metas do compromisso e receber o apoio técnico / financeiro do MEC [Ministério da Educação], para que a educação brasileira dê um salto de qualidade. (BRASIL, 2008, p. 4).

Sabendo que o Índice de Desenvolvimento da Educação Básica (IDEB) é calculado com base nos dados sobre aprovação escolar, obtidos por meio do Censo Escolar, somado às médias de desempenho nas avaliações do Instituto Nacional de Estudos e Pesquisa - INEP -(Saeb e Prova Brasil), vemos explicitado o atrelamento entre avaliações em larga escala e currículo, na medida em que a participação das escolas, das redes e dos sistemas de ensino em avaliações além de compulsória -, vincula também apoio técnico-financeiro entre o MEC e os entes federados.

Por seu turno, a definição das matrizes de referência dos conteúdos, das habilidades e dos procedimentos para a elaboração das avaliações também é representativa dessa relação, uma vez que

[...] as matrizes de referência não englobam todo o currículo escolar. É feito um recorte com base no que é possível aferir por meio do tipo de instrumento de medida utilizado na Prova Brasil e que, ao mesmo tempo, é representativo do que está contemplado nos currículos vigentes no Brasil. (BRASIL, 2008, p. 17).

Entretanto, a grande questão é: Quem molda quem? Os currículos vigentes "moldam" e representam a avaliação, ou a avaliação em larga escala (re)direciona e molda o currículo em curso? Mais adiante, o mesmo documento informa que: "Essas matrizes têm por referência os Parâmetros Curriculares Nacionais e foram construídas a partir de uma consulta nacional aos currículos propostos pelas Secretarias Estaduais de Educação e por algumas redes municipais" (BRASIL, 2008, p. 17). 
As críticas e as resistências ao modelo e às relações dele advindas também compõem o discurso oficial e a pronúncia da veridicção, quando:

\begin{abstract}
Lamentavelmente, esses questionamentos não têm indicado alternativas para $o$ aperfeiçoamento das avaliações nacionais. Como se sabe, as avaliações ENEM e Prova Brasil vem-se constituindo em políticas de Estado que subsidiam os sistemas na formulação de políticas públicas de equidade, bem como proporcionam elementos aos municípios e escolas para localizarem as suas fragilidades e promoverem ações, na tentativa de superá-las, por meio de metas integradas. Além disso, é proposta do CNE [Conselho Nacional de Educação] o estabelecimento de uma Base Nacional Comum que terá como um dos objetivos nortear as avaliações e a elaboração de livros didáticos e de outros documentos pedagógicos. (BRASIL, 2010, p. 7-8, grifos nossos).
\end{abstract}

Dessa forma, os currículos, pelo viés aqui proposto, aparecem como uma verdade necessária ao exercício do poder, algo que ampara, justifica, propõe ou impõe práticas de gestão e práticas pedagógicas, que mobiliza esforços, que encaminha opiniões e decisões. O cálculo é simples e lógico: se um aluno, uma escola, uma rede e um sistema de ensino terão sua qualidade atestada pelo produto de um procedimento avaliativo padronizado, sobre o qual as matrizes de referência já foram dadas, por qual razão os mesmos sujeitos adotarão um currículo com conteúdos diversos daqueles, ainda que tais conteúdos possam ser mais adequados e significativos?

Trata-se de uma verdade, em sua eficácia política, mas nada garante que seja uma fiel descrição dos fatos, que seja, em um sentido tradicional, "de fato verdadeira", como pontua Veyne (2009). Radicalizando tal olhar crítico, caberia contestar a própria existência, para além de uma dimensão tão somente discursiva, possível somente na atual conjuntura política, econômica e cultural, desse atributo então denominado "qualidade" que tais recursos visam constatar.

\title{
Resultados (por natureza, sempre provisórios) da investigação
}

Ao promover uma crítica do poder, Foucault inova ao propor a positividade de sua ação, não se alinhando a diversas leituras que salientam tão somente as propriedades restritivas e violentas do poder. Entretanto, isso não significa uma contemplação passiva de seus efeitos, mesmo que positivos, como é o caso dos poderes atuantes em grande parte da esfera educacional. Afirma o autor que "[...] não se trata de dizer que todo poder é ruim, mas de dizer, ou de partir desse ponto: qualquer poder, qualquer que ele seja, não é de pleno direito aceitável ou não é absolutamente e definitivamente inevitável" (FOUCAULT, 2009, p. 35), dado que "[...] não existe legitimidade intrínseca do poder" (FOUCAULT, 2009, p. 34). Ele só se justifica no arranjo histórico de sua existência.

Qualquer crítica dessa ordem não pode almejar "desmantelar o poder" ou relativizar toda e qualquer verdade; entretanto, "[...] contestar un discurso, 'descalificar unos enunciados' puede ayudar a derrocar el dispositivo que los apoya” (VEYNE, 2009, p. 108, grifo do autor). Ou seja, por mais modesto que seja o objetivo de uma crítica, ela pode fragilizar práticas que promovem subjetivação, abrindo perspectivas para novas experiências. No caso em tela, as avaliações em larga escala são capazes mesmo de moldar - implícita ou explicitamente - o currículo escolar, impondo-se como porta-voz da verdade em relação ao projeto de sociedade em pauta.

Ao buscar aprimorar as práticas educacionais, cabe apreciar criticamente os elementos que balizam qualquer ato político, mesmo que subjacente a uma "análise técnica" (ou um ritual de 
veridicção?), como é o caso das aferições acerca da qualidade educacional. Verdades precisam ser postas em suspenso, livrando-as de qualquer atributo transcendental.

Urge verificar, tomando o caso aqui debatido, se aquilo que se expressa em currículos escolares atualmente adotados é, de fato, o que deseja e representa a heterogeneidade dos sujeitos envolvidos, como destino para a educação, ou se as avalições em larga escala tomaram uma proporção maior que sua própria essência - de verificação de qualidade - representando, ela própria, a qualidade e narrando, substantivamente, o que deve ser espelho homogêneo dessa qualidade, constituindo-a no âmbito dos discursos e das práticas.

\section{Referências}

ANDRADE, E. C. Rankings em educação: tipos, problemas, informações e mudanças. Estudos Econômicos, São Paulo, v. 41, n. 2, p. 323-343, abr./jun. 2011.

BALL, S. J. Performatividade, privatização e o pós-Estado do Bem-Estar. Educação \& sociedade, Campinas, v. 25, n. 89, p. 1105-1126, set./dez. 2004. DOI: 10.1590/s010173302004000400002

BALL, S. J. Performatividades e fabricações na economia educacional: rumo a uma sociedade performativa. Educação \& Realidade, Campinas, n. 35, v. 2, p. 37-55, mai./ago. 2010.

BARDIN, L. Análise de Conteúdo. Tradução de Luiz Antero Reto e Augusto Pinheiro. Lisboa: Edições 7, 2007.

BERTRAND, D. Caminhos da semiótica literária. Bauru: EDUSC, 2003.

BRASIL. Ministério da Educação. Parecer CNE/CEB No 7, de 7 abril de 2010. Diretrizes Curriculares Nacionais Gerais para a Educação Básica. 2010. Disponível em: $<$ http://portal.mec.gov.br/index.php?option $=$ com_docman\&view $=$ download\&alias $=5367$ pceb007-10\&category_slug=maio-2010-pdf\&Itemid=30192>. Acesso em: 12 nov. 2015.

BRASIL. Ministério da Educação. Plano de Desenvolvimento da Educação - PDE: SAEB: ensino médio: matrizes de referência, tópicos e descritores. Brasília: MEC, SEB; Inep, 2008.

BRASIL. Ministério da Educação. Qualidade da Educação: uma nova leitura do desempenho dos estudantes da $3^{\text {a }}$ série do ensino médio. Brasília: MEC/Inep, 2004. Disponível em: $<$ http://download.inep.gov.br/download/saeb/2004/qualidade_educacao.pdf >. Acesso em: 23 nov. 2015.

CASTRO, E. Vocabulário de Foucault: um percurso sobre seus temas, conceitos e autores. Belo Horizonte: Autêntica, 2009.

FERREIRA, R. A.; TENÓRIO, R. M. A construção de indicadores de qualidade no campo da avaliação educacional: um enfoque epistemológico. Revista Lusófona de Educação, Lisboa, v. 15, n. 15, p. 71-97, 2010.

FOUCAULT, M. Vigiar e punir. 3. ed. Petrópolis: Vozes, 1984. 
FOUCAULT, M. Microfísica do poder. 17. ed. Rio de Janeiro: Graal, 2002a.

FOUCAULT, M. A verdade e as formas jurídicas. 3. ed. Rio de Janeiro: Nau, 2002b.

FOUCAULT, M. A ordem do discurso. 8. ed. São Paulo: Loyola, 2002c.

FOUCAULT, M. Do governo dos vivos. São Paulo: Centro de Cultura Social, 2009.

FOUCAULT, M. O governo de si e dos outros. São Paulo: Martins Fontes, 2011.

LOPES, A. C. Políticas de integração curricular. Rio de Janeiro: UERJ, 2008.

MACHADO, R. Foucault, a ciência e o saber. 3. ed. Rio de Janeiro: Zahar, 2007.

MASSON, G. Orientações para o desenvolvimento de investigação em políticas educativas a partir da teoria marxista. In: TELLO, C.; ALMEIDA, M. L. P. de. (Orgs.). Estudos epistemológicos no campo da pesquisa em política educacional. Campinas: Mercado de Letras, 2013. p. 55-76.

SACRISTÁN, J. G. O currículo: uma reflexão sobre a prática. Porto Alegre: Artmed, 2000.

SILVA, Tomaz T. Documentos de identidade: uma introdução às teorias do currículo. 2. ed. 11. reimp. Belo Horizonte: Autêntica, 2007.

TELLO, C. Las epistemologías de la política educativa: vigilancia y posicionamiento epistemológico del investigador en política educativa. Práxis Educativa, Ponta Grossa, v. 7, n. 1, p. 53-68, jan./jun. 2012. DOI: 10.5212/praxeduc.v.7i1.0003

TELLO, C.; MAINARDES, J. Revisitando o enfoque das epistemologias da política educacional. Práxis Educativa, Ponta Grossa, v. 10, n. 1, p. 153-178, jan./jun. 2015. DOI: 10.5212/praxeduc.v.10i1.0007

VEYNE, P. Foucault: pensamento y vida. Barcelona: Paidós, 2009.

VIANNA, H. M. Fundamentos de um Programa de Avaliação Educacional. Brasília: Liber Livro, 2005.

YAZBEK, A. C. Dez lições sobre Foucault. 2. ed. Petrópolis: Vozes, 2012. 